\title{
Aerosol effective density measurement using scanning mobility particle sizer and quartz crystal microbalance with the estimation of involved uncertainty
}

\author{
Bighnaraj Sarangi ${ }^{1,2}$, Shankar G. Aggarwal ${ }^{1,2}$, Deepak Sinha ${ }^{3}$, and Prabhat K. Gupta ${ }^{2}$ \\ ${ }^{1}$ Academy of Scientific and Innovative Research (AcSIR), CSIR-National Physical Laboratory Campus, \\ New Delhi, 110012, India \\ ${ }^{2}$ Analytical Chemistry Section, CSIR-National Physical Laboratory, New Delhi 110012, India \\ ${ }^{3}$ Government Nagarjun Post Graduate Science College, Raipur 492010, India
}

Correspondence to: Shankar G. Aggarwal (aggarwalsg@ nplindia.org)

Received: 2 October 2015 - Published in Atmos. Meas. Tech. Discuss.: 8 December 2015

Revised: 11 February 2016 - Accepted: 15 February 2016 - Published: 4 March 2016

\begin{abstract}
In this work, we have used a scanning mobility particle sizer (SMPS) and a quartz crystal microbalance (QCM) to estimate the effective density of aerosol particles. This approach is tested for aerosolized particles generated from the solution of standard materials of known density, i.e. ammonium sulfate (AS), ammonium nitrate (AN) and sodium chloride (SC), and also applied for ambient measurement in New Delhi. We also discuss uncertainty involved in the measurement. In this method, dried particles are introduced in to a differential mobility analyser (DMA), where size segregation is done based on particle electrical mobility. Downstream of the DMA, the aerosol stream is subdivided into two parts. One is sent to a condensation particle counter (CPC) to measure particle number concentration, whereas the other one is sent to the QCM to measure the particle mass concentration simultaneously. Based on particle volume derived from size distribution data of the SMPS and mass concentration data obtained from the QCM, the mean effective density $\left(\rho_{\text {eff }}\right)$ with uncertainty of inorganic salt particles (for particle count mean diameter (CMD) over a size range $10-478 \mathrm{~nm}$ ), i.e. $\mathrm{AS}, \mathrm{SC}$ and $\mathrm{AN}$, is estimated to be $1.76 \pm 0.24,2.08 \pm 0.19$ and $1.69 \pm 0.28 \mathrm{~g} \mathrm{~cm}^{-3}$, values which are comparable with the material density $(\rho)$ values, 1.77 , 2.17 and $1.72 \mathrm{~g} \mathrm{~cm}^{-3}$, respectively. Using this technique, the percentage contribution of error in the measurement of effective density is calculated to be in the range of 9-17\%. Among the individual uncertainty components, repeatability of particle mass obtained by the QCM, the QCM crys-
\end{abstract}

tal frequency, CPC counting efficiency, and the equivalence of CPC- and QCM-derived volume are the major contributors to the expanded uncertainty (at $k=2$ ) in comparison to other components, e.g. diffusion correction, charge correction, etc. Effective density for ambient particles at the beginning of the winter period in New Delhi was measured to be $1.28 \pm 0.12 \mathrm{~g} \mathrm{~cm}^{-3}$. It was found that in general, mid-day effective density of ambient aerosols increases with increase in CMD of particle size measurement but particle photochemistry is an important factor to govern this trend. It is further observed that the CMD has good correlation with $\mathrm{O}_{3}, \mathrm{SO}_{2}$ and ambient RH, suggesting that possibly sulfate secondary materials have a substantial contribution in particle effective density. This approach can be useful for real-time measurement of effective density of both laboratory-generated and ambient aerosol particles, which is very important for studying the physico-chemical properties of particles.

\section{Introduction}

The density of atmospheric particles is an important parameter for prediction of particle physical, micro-physical and optical properties (Tang and Munkelwitz, 1994; Baron and Willeke, 2001). It is not only governed by the shape, morphology and mixing state of the particles, but also linked with the chemical composition of particles. The density, combined with the dynamic shape factor (DSF, which is a measure of 
non-sphericity, $\chi)$, relates the aerodynamic diameter $\left(d_{\mathrm{a}}\right)$ of a particle to its electrical mobility diameter $\left(d_{\mathrm{m}}\right)$ through its mass equivalent diameter $\left(d_{\mathrm{M}}\right)$ (Kelly and McMurry, 1992) by

$d_{\mathrm{a}}^{2} C\left(d_{\mathrm{a}}\right) \rho_{0}=d_{\mathrm{m}}^{2} C\left(d_{\mathrm{m}}\right) \frac{\left[C\left(d_{\mathrm{M}}\right)\right]^{3} \times \rho_{\mathrm{p}}}{\left[C\left(d_{\mathrm{m}}\right)\right]^{3} \times \chi^{3}}$,

where $C\left(d_{\mathrm{a}}\right), C\left(d_{\mathrm{m}}\right)$ and $C\left(d_{\mathrm{M}}\right)$ are the Cunningham slip correction factor for corresponding diameters $\left(d_{\mathrm{a}}, d_{\mathrm{m}}\right.$ and $\left.d_{\mathrm{M}}\right), \rho_{0}$ is the standard density $\left(1 \mathrm{~g} \mathrm{~cm}^{-3}\right)$, and $\rho_{\mathrm{p}}$ is the particle density. As given in Eq. (1), combined measurement of mobility and aerodynamic diameters yields the density of particles having any shape. For non-spherical and porous particles, the tendency has been to define an effective density instead (Hand and Kreidenweis, 2002; Jimenez et al., 2003). Effective density reflects both particle density and shape information:

$\rho_{\text {eff }}=\frac{\rho_{\mathrm{p}}}{\chi}$.

This equation suggests that if the particles are spherical with the absence of internal voids (i.e. $\chi=1$ ), then the effective density is equal to the material density. If particles are non-spherical, then the calculated volume or volume concentration surpasses the true value, and the effective density is less than the material density. However, in general effective density is measured assuming that particles are spherical. Therefore the detailed uncertainty budget estimation in particle effective density measurement is very important to better simulate the results of particle properties, which are linked with such measurements.

As a result of aerosol instrumentation advancement in recent decades, several approaches for the real-time measurements of particle effective density have been developed. Hand and Kreidenweis (2002) measured particle optical size $\left(d_{\mathrm{o}}\right)$, and $d_{\mathrm{m}}$, and $d_{\mathrm{a}}$, using an optical particle counter (OPC), a differential mobility analyser (DMA), and an aerodynamic particle sizer (APS), respectively and aligned these sizes in the instrument overlap regions, which allowed them to retrieve particle effective density. Pioneering work was done by McMurry et al. (2002) in which they determined the density of aerosol particles by selecting particles of known mobility diameter $\left(d_{\mathrm{m}}\right)$ using a DMA and subsequently measuring their mass $\left(m_{\mathrm{p}}\right)$ and number concentration using aerosol particle mass analyser (APM) and condensation particle counter (CPC), respectively. Since then, several instrumental approaches have been reported following the measurements of particle mass and mobility-equivalent volume $(V)$ to determine effective density:

$\rho_{\text {eff }}=\frac{m_{\mathrm{p}}}{V}$.

Khlystov et al. (2004) reported a simple algorithm that was developed to combine aerosol size distributions measured using scanning mobility particle sizer (SMPS) and an APS.
Then this integrated SMPS-APS volume concentration and $\mathrm{PM}_{2.5}$ mass concentration measured using a tapered element oscillating microbalance (TEOM) were used to calculate effective density. Katrib et al. (2005) used a SMPS in parallel with an aerosol mass spectrometer (AMS) to measure particle $d_{\mathrm{m}}$, vacuum diameter $\left(d_{\mathrm{va}}\right)$ and $m_{\mathrm{p}}$ to measure effective density. Similarly, Kostenidou et al. (2007) developed an algorithm for the calculation of organic aerosol density in mixed organic-inorganic particles combining the measurements by SMPS and AMS. Kannosto et al. (2008) investigated the mode-resolved density of ultrafine particles measured in boreal forest using an electrical low-pressure impactor (ELPI) for particle mass distribution and SMPS or differential mobility particle sizer (DMPS) operated in parallel for size distribution data. Virtanen et al. (2002) and Maricq and $\mathrm{Xu}$ (2004) adopted a similar technique (ELPI-SMPS) for measurement of the density of diesel exhaust soot particles. Spencer et al. (2007) reported the simultaneous measurements of the effective density and chemical composition of individual ambient particles in Riverside, California by coupling a DMA with an ultrafine aerosol time-of-flight mass spectrometer (UF-ATOFMS).

Olfert et al. (2007) measured the effective density and fractal dimension of particles emitted from a light-duty diesel vehicle fitted with a diesel oxidation catalyst (DOC) using a DMA and Couette centrifugal particle mass analyser (Couette CPMA). Recently Quiros et al. (2015) also used a DMACPMA technique to measure the effective density of particles emitted from five light-duty vehicles. Ovigneur et al. (2011) presented an approach to retrieve stratospheric aerosol densities in the altitude range 10-40 km from SCIAMACHY limb radiance measurements in the spectral range of the $\mathrm{O}_{2} \mathrm{~A}$ absorption band, near $760 \mathrm{~nm}$.

Similarly, more recently a DMA-APM approach to get particle size and mass information, respectively has been extensively applied for particle density measurements in different environments (Geller et al., 2006; Malloy et al., 2009; Lee et al., 2009; Gysel et al., 2011; Nakao et al., 2013; Rissler et al., 2014; Yin et al., 2015).

Although these various instrumental approaches have been applied successfully to different aerosol types for their effective density measurements, very limited information is available on the uncertainty (standard) involved with the data reported. These data suggest that the uncertainty in the measurement of effective density may vary widely from 3 to $30 \%$ (McMurry et al., 2002; Hand and Kreidenweis, 2002; Olfert et al., 2007; Johnson et al., 2014). More importantly, to our best knowledge no report is available on the detailed combined uncertainty budget in such measurements.

In this work, we have developed a simplified approach to determine aerosol effective density by measuring particle size distribution using a SMPS (electrostatic classifier (EC) + DMA + CPC) and simultaneously measuring particle mass using the quartz crystal microbalance (QCM) technique. This approach is demonstrated here with laboratory- 
generated particles of inorganic salt materials whose density is known to estimate the combined uncertainty in the measurement. The setup is then applied for effective density measurement of ambient aerosols in New Delhi for a week. Here we also discuss the variation of effective density of particles with the meteorological parameters and atmospheric gaseous species, and their influences on effective density of ambient aerosols.

\section{Method}

We used a SMPS (TSI 3080) with a QCM (PC-2, California Measurements, Inc.), which is a 10 -stage cascade impactor with cutoff sizes (aerodynamic diameters) from upper to lower stages of $25,12.5,6.4,3.2,1.6,0.8,0.4,0.2,0.1$ and $0.05 \mu \mathrm{m}$.

\subsection{Scanning mobility particle sizer}

The SMPS consists of an electrostatic classifier (EC, TSI 3080, including an impactor $(0.0457 \mathrm{~cm}$, TSI 1502 296) and $\mathrm{Kr}-85$ bipolar charger (TSI 3077), differential mobility analyser (DMA, TSI 3081) and condensation particle counter (CPC, TSI 3788). Different nozzle sizes for different sample flow rates are used in the SMPS, e.g. for flow rate 0.2$0.8 \mathrm{~L} \mathrm{~min}^{-1}, 0.0457 \mathrm{~cm}$ a nozzle size of the impactor is recommended. We use a sample flow rate $0.48 \mathrm{~L} \mathrm{~min}^{-1}$ in all the measurements, the cut-off size $\left(D_{50}\right)$ of the impactor at this flow rate is $472 \mathrm{~nm}$. The aerosol stream enters through the inlet impactor and the resulting particles get neutralized through the bipolar charger (in accordance with the Fuchs equilibrium charge distribution principle). Then this neutral aerosol stream enters to the DMA, where a varying voltage is applied to the DMA rod so that according to the electrical mobility of particles, respective sized particles exit through the slit at the bottom of the DMA. These size-segregated particles then enter the CPC, where particles undergo condensational growth while passing through saturated liquid vapours followed by their detection through optics. Before the density measurement, the DMA was calibrated with 60 and $100 \mathrm{~nm}$ polystyrene latex (PSL) particles (Sarangi et al., 2014). Also the calibration of CPC counts was checked by a gravimetric approach (Aggarwal et al., 2013).

\subsection{Quartz crystal microbalance}

The QCM uses piezoelectric quartz crystal substrates for the collection of particles which enter through an impactor nozzle placed before every stage. Every stage consists of two quartz crystals: one of the crystals, the sensing oscillating crystal is placed close to the nozzle-exit, and it collects particles; the other crystal, the reference crystal, does not collect particles but is there to nullify background frequency, temperature and other effects on both the crystals. The two crystals are identical and have a resonant frequency of $10 \mathrm{MHz}$.
As the particles impact on the sensing crystal, its frequency decreases while the reference crystal frequency remains unchanged. The difference in frequency of the mixer output (which is generally the same amount of decrease as in the sensing crystal frequency) is considered as the change in the frequency. The amount of frequency change of the signal output is directly proportional to the particle mass deposited on the sensing crystal. The QCM uses the following information to determine particle concentration: the initial frequency before particle collection, the frequency after particle collection (the final frequency), and the sampling time. The QCM design was verified and calibrated at Los Alamos National Laboratory and the Aerosol Laboratory, ULCA.

\subsection{Experimental setup}

The experimental setup used in this study is shown in Fig. 1. For validation of the method, standard materials (inorganic salts) of known density were used. Solution of a standard material was aerosolized by an atomizer (TSI 3076) using 5N purity $\mathrm{N}_{2}$ gas, and the generated aerosol stream was passed through two diffusion dryers placed in series. This dried aerosol stream $(\mathrm{RH}<5 \%)$ was then introduced to the SMPS (through the inlet impactor). Downstream of the DMA, the aerosol flow was subdivided into two parts. One was connected to the CPC and other one to the QCM, which were placed at equal distances from the DMA (the tube length between DMA exit and inlet of CPC or QCM was $25 \mathrm{~cm}$ ). The sample flow rate of the SMPS was set to $0.48 \mathrm{~L} \mathrm{~min}^{-1}$, which is a sum of flow rates of the CPC and the QCM, i.e. $0.24 \mathrm{~L} \mathrm{~min}^{-1}$ each. The purpose of selecting $0.24 \mathrm{~L} \mathrm{~min}^{-1}$ for the CPC is to keep its flow rate equal to the flow rate of the QCM (which works only at $0.24 \mathrm{~L} \mathrm{~min}^{-1}$ for better size segregation). Sheath flow rate of the SMPS was set to $4.8 \mathrm{~L} \mathrm{~min}^{-1}$. Particles of size range $10-478 \mathrm{~nm}$ were segregated by the DMA and number concentration was measured by the CPC. Simultaneously, the corresponding mass distribution was obtained from the QCM. For the calculation of effective density, we used count mean diameter (CMD) derived from the size distribution scan over a size range 10 $478 \mathrm{~nm}$ of the CPC and the real-time corresponding mass concentration obtained from the QCM downstream of the DMA. In this approach, we assumed that particles are spherical $(\chi=1$, Eq. 1$)$, thus the electrical mobility diameter $\left(d_{\mathrm{m}}\right.$, related to DMA size segregation) is equivalent to the aerodynamic diameter $\left(d_{\mathrm{a}}\right.$, related to QCM size segregation, based on impaction theory). It is important to note, however, that uncertainty due to this assumption is added to the combined uncertainty estimation (see Sect. 3.2.2).

Based on the particle size distribution obtained from the SMPS and corresponding mass concentration measured from the QCM, we calculated the effective density of particles us- 


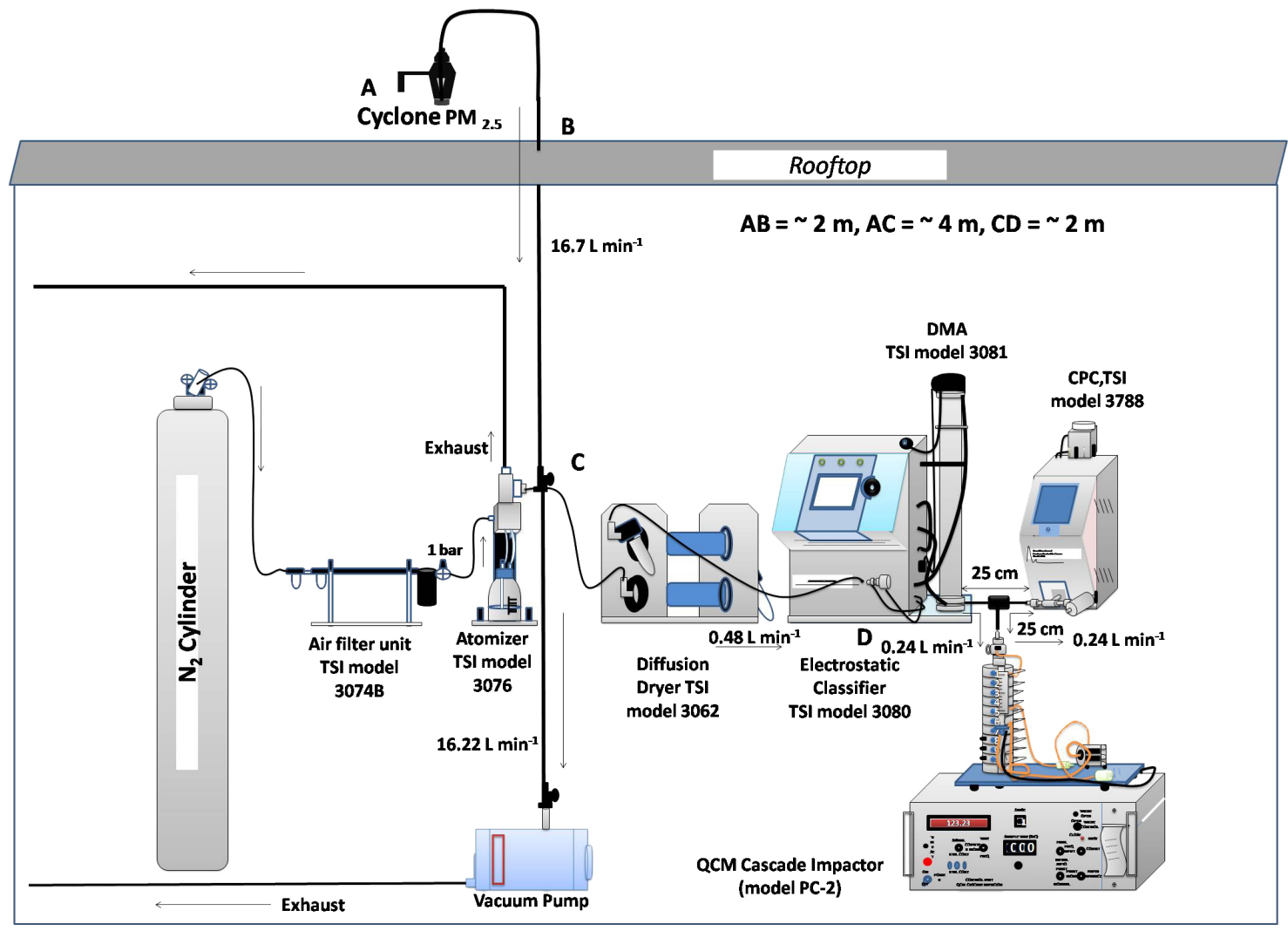

Figure 1. Measurement setup of effective density measurement of laboratory-generated particles and ambient aerosols.

ing Eq. (3):

$$
\rho_{\mathrm{eff}}=\frac{m_{\mathrm{p}}}{V}=\frac{m_{\mathrm{p}}}{\frac{\pi}{6} \times\left(\frac{\sum_{i} d_{\mathrm{m}, i} \times N_{i}}{\sum_{i} N_{i}}\right)^{3} \times \sum_{i} N_{i}},
$$

where $m_{\mathrm{p}}$ is the total mass concentration of the particles measured by the QCM downstream of the DMA. The $d_{\mathrm{m}, i}$ and $N_{i}$ are the mobility diameter of particles and their corresponding number concentration in size bin $i$, respectively.

\subsection{Inorganic salts used}

To validate the measurement of particle effective density using the proposed setup, standard materials of known density were used. These materials were used to prepare solutions $(0.001 \% w / v)$ using Milli-Q water $(>18 \mathrm{M} \Omega \mathrm{cm})$. This solution was nebulized (at 0.7 bar pressure) to generate particles. The details of the material used are summarized in Table 1.

\subsection{Estimation of uncertainty in effective density measurement}

The uncertainty due to different components belonging to particle mass measurement by QCM and volume measurement by $\mathrm{CPC}$ are taken into consideration in the measure- ment of effective density of laboratory-generated aerosol particles (AS, SC and AN), Fig. 2. The combined standard uncertainty $\left(u_{\mathrm{c}}\right)$ can be defined as

$u_{\mathrm{c}}=\sqrt{\sum_{i}\left(u_{i}\right)^{2}}$

$U_{\mathrm{e}}=k \times u_{\mathrm{c}}$,

where $u_{i}$ is the standard uncertainty of the component $i$ and $U_{\mathrm{e}}$ is the expanded uncertainty at $k$ (coverage factor). In this study, $k=2$ at $95 \%$ confidence level. Details of the estimation of uncertainty are discussed in the following sections.

\subsection{Effective density measurement of ambient aerosols}

The experimental setup used to measure effective density of ambient aerosols using the proposed approach is shown in Fig. 1. The measurement was performed for urban aerosols in New Delhi at the National Physical Laboratory (NPL) for the week of 12-18 November 2014. The measurement site is known to be a good representative site of urban aerosols in Delhi with the combined influence of residential, agricultural, traffic and industrial emissions (Sarangi et al., 2015). Also, meteorological data during mid-November in Delhi is known to be representative of the year-round average data. Aerosol samples were aspirated at the rooftop of the lab- 
Table 1. Inorganic salts used for the measurement of density using the SMPS-QCM approach.

\begin{tabular}{|c|c|c|c|c|c|c|}
\hline Inorganic salt & Molecular formula & $M_{\mathrm{W}}\left(\mathrm{g} \mathrm{mol}^{-1}\right)$ & $\rho\left(\mathrm{g} \mathrm{cm}^{-3}\right)$ & $\begin{array}{l}\text { Maximum number } \\
\text { of ions }\end{array}$ & Supplier & Purity \\
\hline Ammonium sulfate & $\left(\mathrm{NH}_{4}\right)_{2} \mathrm{SO}_{4}$ & 132.1 & 1.77 & 3 & MERCK & $>99.5 \%$ \\
\hline Sodium chloride & $\mathrm{NaCl}$ & 80.1 & 2.17 & 2 & Sigma Aldrich & $>99.5 \%$ \\
\hline Ammonium nitrate & $\mathrm{NH}_{4} \mathrm{NO}_{3}$ & 58.4 & 1.72 & 2 & MERCK & $>99.5 \%$ \\
\hline
\end{tabular}

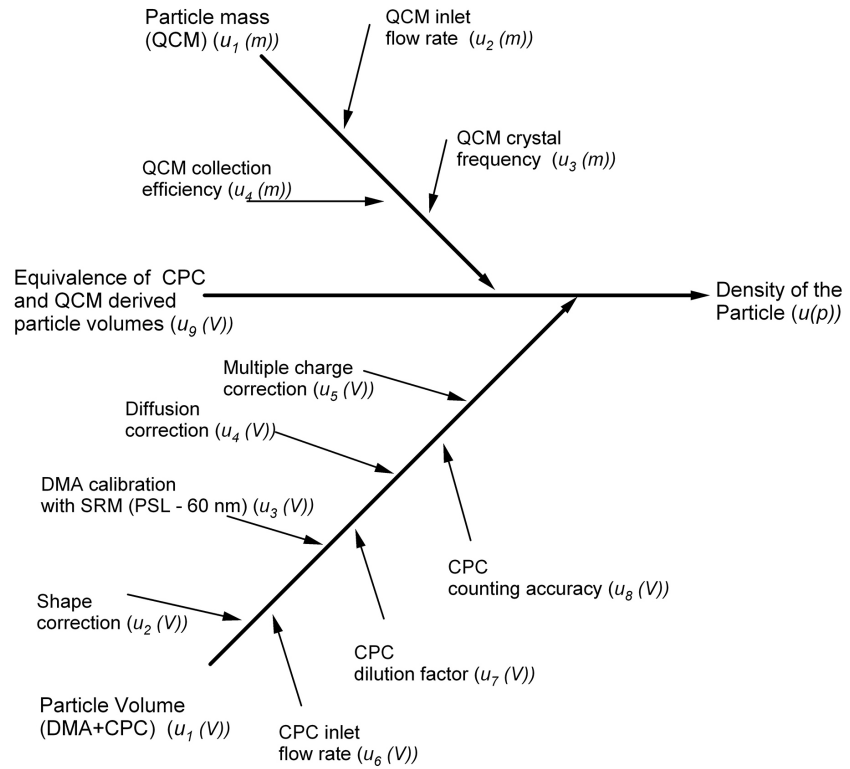

Figure 2. Cause-effective diagram of the uncertainty components considered in this study, constituting the entire uncertainty budget in the measurement of $\rho_{\text {eff }}$ using the SMPS-QCM approach.

oratory ( $\sim 15 \mathrm{~m}$ above the ground) through a cyclone inlet ( $2.5 \mu \mathrm{m}$ cutoff size) connected with copper tubing of internal diameter $6 \mathrm{~mm}$ and length $\sim 4 \mathrm{~m}$. Then aerosols were dried after passing through two diffusion dryers before they reached the inlet impactor of the SMPS.

\subsection{Meteorological data}

Hourly meteorological data (temperature, relative humidity, wind speed and direction) and concentration of atmospheric gases, i.e. sulfur dioxide $\left(\mathrm{SO}_{2}\right)$, carbon monoxide $(\mathrm{CO})$, ozone $\left(\mathrm{O}_{3}\right)$ and nitrogen oxides $\left(\mathrm{NO}_{x}\right)$ for the study period are obtained from a continuous ambient air quality monitoring station (CAQMS) of the Central Pollution Control Board (CPCB), Shadipur located within $3 \mathrm{~km}$ radius from the measurement site (http://www.cpcb.gov.in/ CAAQM/mapPage/frmindiamap.aspx).

\section{Results and discussion}

\subsection{Laboratory test}

Laboratory tests of effective density measurement using the proposed SMPS-QCM setup were performed with three different inorganic salts: ammonium sulfate (AS), sodium chloride (SC) and ammonium nitrate (AN). Before the density measurement of inorganic salt materials, the DMA was calibrated using particle size standards (PSL 60 and $100 \mathrm{~nm}$ ), which are traceable to SI through the National Institute of Standards and Technology (NIST), USA. Counting efficiency of the CPC was checked using a filter-based gravimetric approach, which is discussed elsewhere (Aggarwal et al., 2013). Crystals of all the stages of the QCM were tested for background frequency prior to measurements. As per the QCM instrumental guidelines, background frequency of the crystals of all the stages was set to between 2 and $4 \mathrm{kHz}$ for a valid measurement.

Effective density is estimated from the SMPS-derived volume and QCM-measured mass using Eq. (4). Figure 3 shows the effective density $\left(\mathrm{g} \mathrm{cm}^{-3}\right)$ versus count mean diameter (CMD) for AS, SC and AN particles. The mean effective particle densities with standard deviation were determined to be $1.76 \pm 0.04,2.08 \pm 0.12$ and $1.69 \pm 0.17 \mathrm{~g} \mathrm{~cm}^{-3}$ for AS, SC and AN particles, respectively. Number concentration and detailed statistics are shown in Table 2. The results indicate that the measured effective density of laboratorygenerated inorganic salt particles using the SMPS-QCM approach agrees well with the reported value in the literature (Svenningsson et al., 2006; Schmid et al., 2009; Schkolnik et al., 2007).

\subsection{Detailed uncertainty calculations}

Because the measurement of particle effective density using the SMPS-QCM approach (Eq. 4) is based on (i) particle mass measurement using the QCM and (ii) particle volume measurement using DMA + CPC, therefore the uncertainty in density measurement involves the components which comprise these two measurements. These components are shown in the cause-effective diagram in Fig. 2.

The uncertainties due to different parameters involved during the measurement of effective density are estimated for laboratory-generated aerosol particles (of AS, SC and AN). The combined standard uncertainty for the measurement of 
Table 2. Measured effective density of laboratory-generated inorganic salt particles.

\begin{tabular}{|c|c|c|c|c|c|c|c|}
\hline \multirow[t]{2}{*}{$\begin{array}{l}\text { Inorganic } \\
\text { salts }\end{array}$} & \multirow[t]{2}{*}{$\begin{array}{l}\text { Density }(\rho) \text { from } \\
\text { literature }\left(\mathrm{g} \mathrm{cm}^{-3}\right)\end{array}$} & \multicolumn{4}{|c|}{$\begin{array}{l}\text { Effective density }\left(\rho_{\text {eff }}\right) \pm \text { SD measured } \\
\text { using the SMPS-QCM approach }\left(\mathrm{g} \mathrm{cm}^{-3}\right)\end{array}$} & \multirow[t]{2}{*}{$\begin{array}{c}\text { Mean CMD } \pm \text { SD } \\
(\mathrm{nm})\end{array}$} & \multirow{2}{*}{$\begin{array}{c}\text { Mean number } \\
\text { concentration }\end{array}$} \\
\hline & & Mean & Max & Min & $\% \mathrm{SD}$ & & \\
\hline$\left(\mathrm{NH}_{4}\right)_{2} \mathrm{SO}_{4}$ & 1.77 & $1.76 \pm 0.04$ & 1.86 & 1.66 & 2.27 & $33.17 \pm 0.43$ & 4.6 \\
\hline $\mathrm{NaCl}$ & 2.17 & $2.08 \pm 0.12$ & 2.19 & 1.91 & 5.76 & $33.17 \pm 0.21$ & 8.3 \\
\hline $\mathrm{NH}_{4} \mathrm{NO}_{3}$ & 1.72 & $1.69 \pm 0.17$ & 1.92 & 1.51 & 10.1 & $31.20 \pm 0.33$ & 2.3 \\
\hline
\end{tabular}
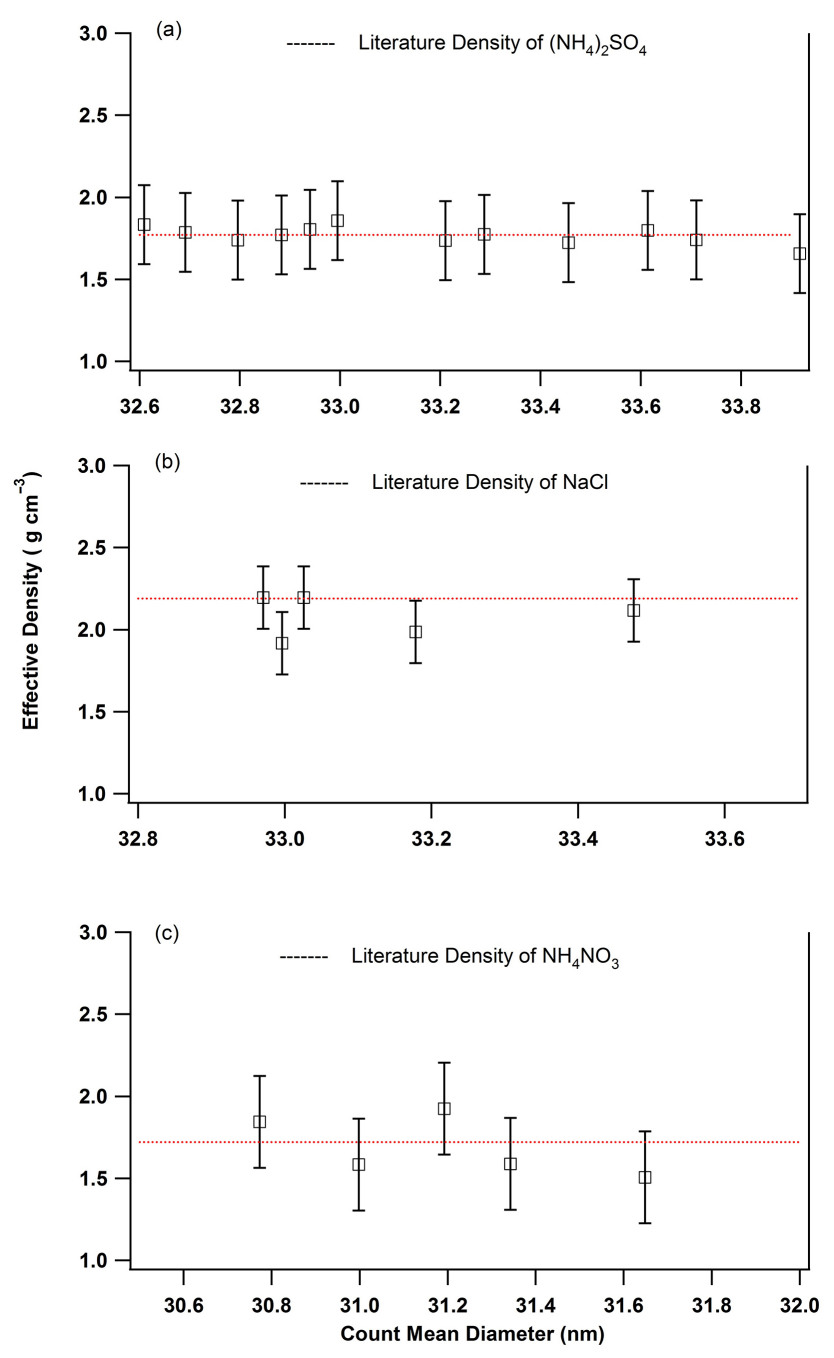

Figure 3. Laboratory-generated inorganic salt particle effective density versus count mean diameter over the size range $10-478 \mathrm{~nm}$ : (a) ammonium sulfate, (b) sodium chloride and (c) ammonium nitrate.

effective density $(u(\rho))$ can be expressed as

$$
\frac{u(\rho)}{\rho}=\sqrt{\left(\frac{u(m)}{m}\right)^{2}+\left(\frac{u(V)}{V}\right)^{2}},
$$

where $\frac{u(\rho)}{\rho}, \frac{u(m)}{m}$ and $\frac{u(V)}{V}$ represent the combined relative standard uncertainty in density, mass and volume of the particles, respectively. Using Eq. (7) the combined standard uncertainty in the measurement of effective density of AS, SC and $\mathrm{AN}$ was estimated to be $0.24,0.19$ and $0.28 \mathrm{~g} \mathrm{~cm}^{-3}$. The detailed uncertainty budget for the estimation of uncertainty in measurement of $\rho_{\text {eff }}$ of all the inorganic salts species considered in this study (i.e. AS, SC and AN) is shown in Table 3. In what follows we discuss the individual combined relative standard uncertainty for both mass and volume for ammonium sulfate particles as an example.

\subsubsection{Uncertainty in particle mass measurement using QCM}

The mass concentration of monodisperse inorganic salt particles (downstream of the DMA) is obtained by QCM. The QCM uses the following information to determine particle concentration: (i) the initial frequency before particle collection, (ii) the frequency after particle collection (the final frequency) and (iii) the sampling time. Once these are available, the instrument finds the frequency change $(\mathrm{d} F$ in $\mathrm{Hz})$, divides it by the sampling time ( $\mathrm{d} T$ in $\min$ ) and multiplies it by a mass sensitivity constant $\left(K\right.$ in $\left.\mu \mathrm{g} \min \left(\mathrm{Hz} \mathrm{m}^{3}\right)^{-1}\right)$ of an impactor stage, and then finally gives the result of particle mass concentration $\left(m\right.$ in $\left.\mu \mathrm{g} \mathrm{m}^{-3}\right)$ :

$m=K\left(\frac{\mathrm{d} F}{\mathrm{~d} T}\right)$.

Equation (8) represents the mass concentration, which is a function of change in frequency of quartz crystal and the sampling time, and mass sensitivity constant. Therefore, the uncertainty involved in particle mass measurement has significant contributions from these parameters which are discussed in detail in the following sections.

\section{Uncertainty due to mass collected at different stages of QCM}

The mass concentration of the particles is considered to be the summation of the mass concentrations obtained from the different stages of QCM (i.e. total mass, $m_{\mathrm{p}}$ ). This mass concentration is further converted to mass using QCM air volume (the product of inlet flow rate and sampling time). 
Table 3. The uncertainty budget in the measurement of effective density of laboratory-generated inorganic salt particles (ammonium sulfate, AS; sodium chloride, SC; ammonium nitrate, AN).

\begin{tabular}{|c|c|c|c|c|c|c|c|c|c|c|c|}
\hline \multicolumn{12}{|c|}{ Mass measurement by quartz crystal microbalance (QCM) } \\
\hline \multirow[t]{2}{*}{$\begin{array}{l}\text { Source of } \\
\text { uncertainty }\end{array}$} & \multirow[t]{2}{*}{$\begin{array}{l}\text { Uncertainty } \\
\text { type }\end{array}$} & \multicolumn{3}{|c|}{$\begin{array}{c}\text { Standard uncertainty, } \\
u_{i}(m)(\mu \mathrm{g})\end{array}$} & \multirow[t]{2}{*}{ Distribution } & \multicolumn{3}{|c|}{$\begin{array}{l}\text { Relative standard, } \\
\text { uncertainty }\left(\frac{u_{i}(m)}{m}\right)\end{array}$} & \multicolumn{3}{|c|}{$\begin{array}{l}\text { Contribution of relative standard } \\
\text { uncertainty in the combined } \\
\text { relative uncertainty of density } \\
\text { measurement, } \frac{\left(\frac{u_{i}(m)}{m}\right)^{2}}{\left(\frac{u(\rho)}{\rho}\right)^{2}}(\%)\end{array}$} \\
\hline & & AS & $\mathrm{SC}$ & AN & & AS & $\mathrm{SC}$ & AN & AS & $\mathrm{SC}$ & AN \\
\hline$u_{1}(m)$ & Type A & 1.45 & 0.05 & 0.18 & Normal & 0.053 & 0.004 & 0.067 & 15.1 & 0.17 & 16.2 \\
\hline$u_{2}(m)$ & Type A & 0.54 & 0.27 & 0.05 & Normal & 0.019 & 0.019 & 0.011 & 2.14 & 4.81 & 1.42 \\
\hline$u_{3}(m)$ & Type A & 1.01 & 0.49 & 0.09 & Normal & 0.037 & 0.036 & 0.037 & 7.32 & 16.5 & 4.87 \\
\hline$u_{4}(m)$ & Type B & 0.59 & 0.29 & 0.06 & Rectangular & 0.022 & 0.021 & 0.022 & 2.51 & 5.64 & 1.72 \\
\hline \multicolumn{2}{|l|}{ Sampling time } & \multicolumn{7}{|c|}{ Negligible } & & & \\
\hline \multicolumn{12}{|c|}{ Volume measurement by scanning mobility particle sizer (SMPS) } \\
\hline \multirow[t]{2}{*}{$\begin{array}{l}\text { Source of } \\
\text { uncertainty }\end{array}$} & \multirow[t]{2}{*}{$\begin{array}{l}\text { Uncertainty } \\
\text { type }\end{array}$} & \multicolumn{3}{|c|}{$\begin{array}{l}\text { Standard uncertainty, } \\
\left(u_{i}(V)\right) \times 10^{-19}\left(\mathrm{~cm}^{3}\right)\end{array}$} & Distribution & \multicolumn{3}{|c|}{$\begin{array}{c}\text { Relative standard } \\
\text { uncertainty, }\left(\frac{u_{i}(V)}{V}\right)\end{array}$} & \multicolumn{3}{|c|}{$\begin{array}{l}\text { Contribution of relative standard } \\
\text { uncertainty in the combined } \\
\text { relative uncertainty of density } \\
\text { measurement, } \frac{\left(\frac{u_{i}(V)}{V}\right)^{2}}{\left(\frac{u(\rho)}{\rho}\right)^{2}}(\%)\end{array}$} \\
\hline & & AS & $\mathrm{SC}$ & AN & & AS & SC & AN & AS & SC & AN \\
\hline$u_{1}(V)$ & Type A & 2.13 & 1.63 & 2.28 & Normal & 0.011 & 0.008 & 0.014 & 0.67 & 0.89 & 0.74 \\
\hline$u_{2}(V)$ & Type A & 2.12 & 1.63 & 2.28 & Normal & 0.011 & 0.005 & 0.014 & 0.67 & 0.89 & 0.74 \\
\hline$u_{3}(V)$ & Type B & 1.62 & 1.62 & 1.35 & Rectangular & 0.009 & 0.006 & 0.009 & 0.39 & 0.88 & 0.27 \\
\hline$u_{4}(V)$ & Type A & 2.13 & 0.42 & 0.59 & Normal & 0.011 & 0.001 & 0.004 & 0.67 & 0.06 & 0.05 \\
\hline$u_{5}(V)$ & Type A & 2.13 & 1.41 & 1.98 & Normal & 0.011 & 0.004 & 0.012 & 0.68 & 0.67 & 0.56 \\
\hline$u_{6}(V)$ & Type A & 1.82 & 1.04 & 1.51 & Normal & 0.009 & 0.006 & 0.006 & 0.49 & 1.11 & 0.33 \\
\hline$u_{7}(V)$ & Type A & 1.82 & 1.04 & 1.51 & Normal & 0.009 & 0.006 & 0.006 & 0.49 & 1.11 & 0.33 \\
\hline$u_{8}(V)$ & Type B & 12.3 & 10.9 & 9.18 & Rectangular & 0.064 & 0.057 & 0.057 & 22.4 & 40.6 & 12.0 \\
\hline$u_{9}(V)$ & Type B & 17.6 & 8.89 & 20.6 & Rectangular & 0.092 & 0.047 & 0.13 & 46.4 & 26.6 & 60.7 \\
\hline \multicolumn{12}{|c|}{ Density measurement by SMPS-QCM } \\
\hline \multicolumn{6}{|c|}{ Combined standard uncertainty $\left(u_{\mathrm{c}}(\rho)\right)\left(\mathrm{g} \mathrm{cm}^{-3}\right)$} & \multicolumn{6}{|c|}{$\begin{array}{l}\text { Contribution of the combined uncertainty in the } \\
\text { density measurement }\left(\frac{u_{\mathrm{c}}(\rho)}{\rho}\right)(\%)\end{array}$} \\
\hline AS & $\mathrm{SC}$ & & AN & & & AS & & $\mathrm{SC}$ & & AN & \\
\hline 0.24 & 0.19 & & 0.28 & & & 13.6 & & 9.13 & & 16.6 & \\
\hline
\end{tabular}

The uncertainty (type A) in mass measurement $u_{1}(m)$ is estimated using the following equation:

$u_{1}(m)=\frac{\sqrt{\frac{\sum_{i=1}^{n}\left(m_{\mathrm{p}, i}-\bar{m}_{\mathrm{p}}\right)^{2}}{n-1}}}{\sqrt{n}}$,

where $m_{\mathrm{p}, i}$ is the mass of particles obtained from QCM for sample $i$ (i.e. total mass of particles collected on different stages of QCM), $\bar{m}_{\mathrm{p}}$ is the mean mass over $m_{\mathrm{p}, i}$, and $n$ is the number of samples $(n=12)$.
For example, the calculated mean mass of ammonium sulfate (AS) particles is $27.4 \mu \mathrm{g}$, and the estimated standard uncertainty for ammonium sulfate particle mass is $\pm 1.45 \mu \mathrm{g}$.

\section{Uncertainty due to sampling time}

The sampling time of sample $i$ in QCM is $120 \mathrm{~s}$ which is equivalent to SMPS up-scan sampling time for a sample $i$. Because the sampling time for a sample in both QCM and $\mathrm{CPC}$ is the same, uncertainty due to sampling time is equally contributed to mass and volume measurements, respectively, and hence assumed to nullify the effect in effective density 
measurement result. Therefore we have not considered this component in the uncertainty estimation.

\section{Uncertainty due to QCM inlet flow rate}

The QCM inlet flow $\left(0.24 \mathrm{~L} \mathrm{~min}^{-1}\right)$ is calibrated with the reference flow meter (Gilian Gilibrator2, SP100IZ, World Precision Instruments) traceable to SI unit through NIST, USA. Standard uncertainty in flow rate $(u(q))$ at the inlet of the QCM during sampling is estimated using the following equation:

$u(q)=\frac{\sqrt{\frac{\sum_{i=1}^{n}\left(q_{i}-\bar{q}\right)^{2}}{n-1}}}{\sqrt{n}}$,

where $q_{i}$ is the QCM inlet flow rate during sample $i$, and $\bar{q}$ is the mean flow rate measured during the whole duration of sampling (for $n$ number of samples).

The uncertainty contribution in mass of AS particles due to the QCM inlet flow rate is $\pm 1.98 \%$. The percentage is calculated as $\frac{u(q)}{\bar{q}} \%$. The corresponding standard uncertainty $u_{2}(m)$ (type A uncertainty based on repeatable measurement and normal distribution) is estimated to be $\pm 0.54 \mu \mathrm{g}$ using the following equation:

$u_{2}(m)=\bar{m} \times \frac{u(q)}{\bar{q}} \times 0.01$.

\section{Uncertainty due to variation in crystal frequency}

In the QCM, each impactor stage constitutes a nozzle, two open-face quartz crystals, and electronics circuits for the crystals. One of the crystals, the sensing crystal, is placed close to the nozzle exit and collects particles. The other crystal, the reference crystal, does not collect particles but is there to nullify temperature or other effects on both crystals. The amount of frequency change of the signal output is in direct proportion to the particle mass deposited on the sensing crystal. Therefore, the frequency of each stage of QCM is continuously monitored prior to and after the sampling. The uncertainty due to crystal frequency $u(\Delta f)$ is estimated using Eq. (12) below, which is based on the deviation in mean frequency difference of sensing and reference crystals of all the stages of the QCM:

$u(\Delta f)=\frac{\sqrt{\frac{\sum_{i=1}^{n}\left(\Delta f_{i}-\overline{\Delta f}\right)^{2}}{n-1}}}{\sqrt{n}}$,

where $\Delta f_{i}$ is the mean frequency difference between sensing and reference crystals of all the stages of the QCM for sample $i$, the $\overline{\Delta f}$ is the mean over $\Delta f_{i}$, and $n$ is the total number of observations during the whole duration of sampling.

The uncertainty contribution in mass of AS particles due to variation in crystal frequency is $\pm 3.7 \%$. The percentage is calculated as $\frac{u(\Delta f)}{\overline{\Delta f}} \%$. The corresponding standard uncertainty, $u_{3}(m)$ (type A and normal distribution) is estimated to be $\pm 1.01 \mu \mathrm{g}$ using

$u_{3}(m)=\bar{m} \times \frac{u(\Delta f)}{\overline{\Delta f}} \times 0.01$.

\section{Uncertainty due to QCM collection efficiency}

The QCM (PC-2) is a 10-stage impactor and the collection efficiencies for all stages are reported by Horton et al. (1992). In this study we have assumed that the collection efficiencies of all the stages are a function of particle diffusion loss. The percentage uncertainty contribution in the mass of ammonium sulfate due to QCM collection efficiencies is $\pm 3.73 \%$. This percentage is a mean value of the collection efficiencies of all the stages as reported by Horton et al. (1992), and was not measured during the sampling in this work. Hence the uncertainty contribution is considered as type B uncertainty. The corresponding standard uncertainty (i.e. $u_{4}(m)$ ) assuming rectangular distribution is estimated to be $\pm 0.59 \mu \mathrm{g}$ for AS particles:

$u_{4}(m)=\bar{m}_{\mathrm{p}} \times 3.73 \times 0.01 \times \frac{1}{\sqrt{3}}$.

The combined relative standard uncertainty $\left(\frac{u(m)}{m}\right)$ in particle mass measurement using QCM including both type A and type B is estimated by

$\frac{u(m)}{m}=\sqrt{\sum_{i}\left(\frac{u_{\mathrm{A}, i}(m)}{m}\right)^{2}+\sum_{i}\left(\frac{u_{\mathrm{B}, i}(m)}{m}\right)^{2}}$

where $u_{\mathrm{A}, i}(m)$ (i.e. $u_{1}(m), u_{2}(m)$ and $\left.u_{3}(m)\right)$ and $u_{\mathrm{B}, i}(m)$ (i.e. $\left.u_{4}(m)\right)$ are the standard uncertainty sources from type $\mathrm{A}$ and type $\mathrm{B}$, respectively. The estimated combined relative standard uncertainty in the measurement of AS particle mass using Eqs. (9)-(15) is estimated to be \pm 0.07 .

\subsubsection{Uncertainty in particle volume calculation (using DMA + CPC)}

The SMPS consists of an electrostatic classifier (EC, including an impactor and $\mathrm{Kr}-85$ bipolar charger), a DMA and a CPC. The radioactive source (Kr-85 gas) imposes a Boltzmann charge distribution on aerosol particles. Aerosol particles then pass through the DMA. Here, an electric field acts on the charged particles, such that they are classified according to their electrical mobility equivalent diameter and then the resulting size-selected particles enter the CPC. In the CPC, particles are counted in an optical detector, which uses the scattered light of a laser source focused onto the particle stream (Hinds, 1999). The particle number concentration for every size bin $\left(N_{\text {smps }}\right)$, which is a function of channel raw count $\left(n_{i}^{\prime}\right)$ of the CPC through the CPC dilution factor 
$(\varphi)$, the sampling time $\left(t_{i}\right)$, the sampling flow rate $(\theta)$ and the counting efficiency $\left(\eta_{i}\right)$, and can be represented as (Buonanno et al., 2009)

$N_{\mathrm{smps}, i}=\frac{n_{i}^{\prime} \varphi}{t_{i} \theta \eta_{i}}$.

The channel volume concentration $\left(v_{\mathrm{smps}, i}\right)$ is evaluated from $N_{\mathrm{smps}, i}$ by means of

$$
\begin{aligned}
v_{\mathrm{smps}, i} & =\frac{\pi}{6} d_{\mathrm{ve}, i}^{3} N_{\mathrm{smps}, i}=\frac{\pi}{6} d_{\mathrm{ve}, i}^{3} \frac{n_{i}^{\prime} \varphi}{t_{i} \theta \eta_{i}} \\
& =\frac{\pi}{6} d_{\mathrm{ve}, i}^{3} \frac{\mathrm{d} N_{i}}{\operatorname{dlog} d_{\mathrm{ve}, i}} \Delta w_{i},
\end{aligned}
$$

where $d_{\mathrm{ve}, i}$ represents the equivalent volumetric diameter (the diameter of a sphere having the same volume as the particle under examination), $\mathrm{d} N_{i} / \mathrm{d} \log d_{\mathrm{ve}, i}$ is the normalized number concentration for each channel and $\Delta w_{i}$ represents the channel width.

In this study, the hypothesis of spherical particle is assumed, hence with this approximation, volumetric and mobility diameter are considered to be equal (Sioutas, et al., 1999; McMurry et al., 2002). The total volume concentration through the SMPS ( $\left.V_{\text {smps }}\right)$ is obtained as the sum of volume concentration of $n$ number of bins:

$V_{\mathrm{smps}}=\sum_{i=1}^{n} v_{\mathrm{smps}, i}$

\section{Uncertainty in particle volume estimated from CPC data}

The volume of inorganic salt particles is calculated from the count mean diameter (Hinds, 1999; Sarangi et al., 2015) obtained from the size distribution data of the CPC for a sample $i$, CPC inlet flow rate $\left(0.24 \mathrm{~L} \mathrm{~min}^{-1}\right)$ and DMA up-scan time $(120 \mathrm{~s})$. The mathematical expression for the estimation of standard uncertainty (type A) in volume of the particles is

$u_{1}(V)=\frac{\sqrt{\frac{\sum_{i=1}^{n}\left(V_{i}-\bar{V}\right)^{2}}{n-1}}}{\sqrt{n}}$,

where $V_{i}$ is the volume of AS obtained from CPC samples $i$, and $\bar{V}$ is the mean volume determined from $n$ number of samples.

For AS particles $(n=12)$, the mean volume determined is $1.91 \times 10^{-17} \mathrm{~cm}^{3}$ and the standard uncertainty estimated is $\pm 2.13 \times 10^{-19} \mathrm{~cm}^{3}$.

\section{Uncertainty in volume due to assumption that particles are spherical}

For spherical particles, the dynamic shape factor (DSF, $\chi$ ) is 1 and in most other cases (e.g. non-spherical particles) it is larger than 1. In such cases, the electrical mobility diameter
( $d_{\mathrm{m}}$, considered for DMA size segregation) is not equivalent to the aerodynamic diameter $\left(d_{\mathrm{a}}\right.$, considered for QCM size segregation). Therefore, it is important to estimate the uncertainty due to the DSF in particle volume and thus in particle density measurement.

It is important to note that the DSF is not a constant - it changes with pressure, particle size, and as a result of particle orientation in electric or aerodynamic flow fields. For inorganic salts, such as ammonium sulfate and sodium chloride, the shape correction factor has been taken as 1.04 (Zelenyuk et al., 2006) and 1.08 (Hinds, 1999), respectively. In this study we have assumed the shape factor for ammonium nitrate as 1.08. Therefore, the correction in particle size can be calculated as

$\mathrm{d} d_{\mathrm{m}}=\chi^{\prime} d_{\mathrm{m}, i}-\chi d_{\mathrm{m}, i}$,

where $\mathrm{d} d_{\mathrm{m}}$ is the correction in diameter. $\chi$ and $\chi^{\prime}$ are the DSFs for spherical and original inorganic salt particle (nonspherical), respectively. Therefore correction in the volume $\left(v_{\mathrm{m}}\right)$ of particles can be calculated from the correction in mobility diameter:

$v_{\mathrm{m}}=\frac{\pi}{6} \times\left(\mathrm{d} d_{\mathrm{m}}^{3}\right)$,

and then the standard uncertainty (type A) involved due to $\operatorname{DSF}\left(u_{2}(V)\right)$ is

$u_{2}(V)=\frac{\sqrt{\frac{\sum_{i=1}^{n}\left(v_{\mathrm{m}, i}-\bar{v}_{\mathrm{m}}\right)^{2}}{n-1}}}{\sqrt{n}}$,

where $v_{\mathrm{m}, i}$ is the corrected volume of sample $i$ of CPC data, and $\bar{v}_{\mathrm{m}}$ is the mean corrected volume derived from $n$ number of samples of CPC data.

Based on repeated measurements $(n=12)$, the standard uncertainty involved due to DSF in the measurement of volume of AS particles is $\pm 2.12 \times 10^{-19} \mathrm{~cm}^{3}$.

\section{DMA calibration: uncertainty in volume due to DMA particle size segregation}

In this study, calibration of the DMA was performed using standard polystyrene latex (PSL) 60 and $100 \mathrm{~nm}$ particles, which are traceable to SI through NIST, USA. Here the uncertainty of particle volume using PSL-60 nm is considered because it is used routinely in the calibration of DMA before and after sampling.

Based on the particle size distribution obtained from the SMPS, the observed mode peak is represented by the size peak of standard PSL particles. The experiment was repeated five times on each of 3 different days. The statistical analyses (count mean diameter (CMD), geometric mean diameter (GMD), geometric standard deviation (GSD), mean mode diameter (MD), repeatability and reproducibility) of particle size obtained from size distribution were performed. 
Table 4. The uncertainty budget in the measurement of PSL-60 $\mathrm{nm}$ reference particles.

\begin{tabular}{|c|c|c|c|c|c|}
\hline \multirow[t]{2}{*}{$\begin{array}{l}\text { Source of } \\
\text { uncertainty }(\mathrm{nm})\end{array}$} & \multirow[t]{2}{*}{$\begin{array}{l}\text { Probability } \\
\text { distribution }\end{array}$} & \multicolumn{2}{|c|}{$\begin{array}{c}\text { Standard } \\
\text { uncertainty }(\mathrm{nm})\end{array}$} & \multirow[t]{2}{*}{$\begin{array}{l}\text { Sensitivity } \\
\text { coefficient }\end{array}$} & \multirow[t]{2}{*}{$\begin{array}{l}\text { Degree of } \\
\text { freedom }\end{array}$} \\
\hline & & $\begin{array}{r}\text { Sample } \\
\text { SET-1 }\end{array}$ & $\begin{array}{r}\text { Sample } \\
\text { SET-2 }\end{array}$ & & \\
\hline Mode peak (Repeatability) & Normal-TypeA & 0.380 & 0.420 & 1 & 4 \\
\hline CMD correction & Normal-TypeA & 0.199 & 0.140 & 1 & 4 \\
\hline Diffusion correction & Rectangular-TypeB & 0.161 & 0.118 & 1 & $\infty$ \\
\hline Charge correction & Rectangular-TypeB & 0.109 & 0.119 & 1 & $\infty$ \\
\hline Impactor flow & Rectangular-TypeB & 0.016 & 0.016 & 1 & $\infty$ \\
\hline Sheath flow & Rectangular-TypeB & 0.00004 & 0.00005 & 1 & $\infty$ \\
\hline Bypass flow & Rectangular-TypeB & 0.057 & 0.058 & 1 & $\infty$ \\
\hline Certificate value of SRM 1964 & Normal-TypeB & 0.310 & 0.310 & 1 & $\infty$ \\
\hline Uncertainty (at manufacturer site) & Normal-TypeB & 0.551 & 0.559 & 1 & $\infty$ \\
\hline Reproducibility & Normal-TypeA & 0.274 & 0.274 & 1 & 2 \\
\hline Combined uncertainty & - & 0.750 & 0.763 & & $\infty$ \\
\hline Expanded uncertainty $(k=2)$ & - & 1.500 & 1.525 & & $\infty$ \\
\hline
\end{tabular}

Uncertainty components due to instrument calibration (impactor flow, sheath flow, bypass flow, CPC inlet flow), instrumental measurement (diffusion correction, charge correction, CMD correction, repeatability, reproducibility) and calibration standard (certificate value of particle standard used, calibration uncertainty at the manufacturer site) were included in the budget estimation of the uncertainty in particle size measurement (Table 4; Sarangi et al., 2014):

$u_{3}(V)=\bar{v} \times x_{\mathrm{psl}} \times 0.01 \times \frac{1}{\sqrt{3}}$

$x_{\mathrm{psl}}=\frac{u^{\prime}}{\bar{d}_{\mathrm{psl}}} \times 100$

where $x_{\mathrm{psl}}$ is the percentage of uncertainty in PSL-60 nm particles. $u^{\prime}$ and $\bar{d}_{\mathrm{psl}}$ are the estimated combined standard uncertainty and the obtained mean mode of PSL- $60 \mathrm{~nm}$ by DMA calibration, respectively.

The uncertainty reported for PSL- $60 \mathrm{~nm}$ in certificate is $\pm 0.63 \mathrm{~nm}$ with coverage factor $k=2$. The uncertainty estimated from DMA calibration using PSL-60 nm by Eq. (23) is $55.62 \pm 1.53 \mathrm{~nm}$ (with coverage factor $k=2$ ). The standard uncertainty $u_{3}(V)$ (type $\mathrm{B}$ and rectangular distribution) involved due to PSL- $60 \mathrm{~nm}$ in the measurement of volume of AS particles is $\pm 1.62 \times 10^{-19} \mathrm{~cm}^{3}$.

\section{Uncertainty in volume due to particle diffusion loss}

Diffusion correction was done using a program (TSI-Aerosol Instrument Manager ${ }^{\circledR}$ (AIM) Software) which is based on the loss of the particles along the SMPS channel (particle loss on the impactor inlet, the bi-polar neutralizer, internal plumbing, the tubing to the DMA and CPC). Using the builtin TSI-AIM (version 9.0.0.0, 15:32:53, 11 November 2010) algorithm, the diffusion correction was done and a corrected number concentration of the particles was obtained. Because the particle CMD is the function of particle number concentration (Hinds, 1999), the uncertainty due to diffusion loss of particles, which affects the volume of particles is estimated as

$$
\begin{aligned}
& v_{\mathrm{d}}=\frac{\pi}{6} \times\left(\left(\mathrm{CMD}^{\prime}\right)^{3}-(\mathrm{CMD})^{3}\right) \\
& \mathrm{CMD}^{\prime}=\left(\frac{N^{\prime}}{N}\right) \times \mathrm{CMD},
\end{aligned}
$$

where $v_{\mathrm{d}}$ is the diffusion corrected volume, and $N^{\prime}$ and $N$ are the total particle number concentrations with diffusion correction and without diffusion correction over a size range $10-478 \mathrm{~nm}$, respectively.

The standard uncertainty $\left(u_{4}(V)\right)$ involved due to diffusion correction (type A uncertainty based on repeated measurement and normal distribution) in the measurement of volume is then estimated as

$u_{4}(V)=\frac{\sqrt{\frac{\sum_{i=1}^{n}\left(v_{d, i}-\bar{v}_{d}\right)^{2}}{n-1}}}{\sqrt{n}}$,

where the subscript $i$ denotes individual samples. $\bar{v}_{d}$ is the mean diffusion-corrected volume and $n$ is the total number of samples.

Using Eq. (27), the standard uncertainty $\left(u_{4}(V)\right)$ involved in volume of AS particles $(n=12)$ is estimated to be $\pm 2.13 \times$ $10^{-19} \mathrm{~cm}^{3}$.

\section{Uncertainty in volume due to particle multiple charges}

Multiple charges on a particle increase its mobility. Since the TSI-AIM software assumes that a particle has only one charge, the effect of multiple charges on a particle allows the 
particle to be incorrectly binned into a smaller-sized particle channel. Therefore, multiple charge correction is performed using the built-in TSI-AIM (version 9.0.0.0, 15: 32: 53, 11 November 2010) algorithm (which is based on Wiedensohler, 1988; Kim et al., 2005) that attempts to correct the sample data from the effects of the multiple charged particles. The mathematical expression for estimation of uncertainty in volume due to multiple charges is similar to that for uncertainty due to particle diffusion loss:

$u_{5}(V)=\frac{\sqrt{\frac{\sum_{i=1}^{n}\left(v_{\mathrm{c}, i}-\bar{v}_{\mathrm{c}}\right)^{2}}{n-1}}}{\sqrt{n}}$

$v_{\mathrm{c}}=\frac{\pi}{6} \times\left(\left(\mathrm{CMD}^{\prime \prime}\right)^{3}-(\mathrm{CMD})^{3}\right)$

$\mathrm{CMD}^{\prime \prime}=\left(\frac{N^{\prime \prime}}{N}\right) \times \mathrm{CMD}$,

where $v_{\mathrm{c}, i}$ and $\bar{v}_{\mathrm{c}}$ are the multiple charge-corrected and mean multiple charge-corrected volumes, respectively. $N^{\prime \prime}$ and $N$ are total particle number concentrations with and without multiple charge corrections, respectively.

The standard uncertainty $\left(u_{5}(V)\right)$ involved due to multiple charge correction (type A uncertainty based on repeated measurement and normal distribution) in the measurement of volume of AS particle is $\pm 2.13 \times 10^{-19} \mathrm{~cm}^{3}$.

\section{Uncertainty in particle volume due to CPC inlet flow rate}

The CPC inlet flow $\left(0.24 \mathrm{~L} \mathrm{~min}^{-1}\right)$ is calibrated with the reference flow meter (Gilian Gilibrator2, SP100IZ, World Precision Instruments). Standard uncertainty in flow rate $\left(u\left(q^{\prime}\right)\right.$ at the inlet of the CPC during sampling is estimated using

$u\left(q^{\prime}\right)=\frac{\sqrt{\frac{\sum_{i=1}^{n}\left(q_{i}^{\prime}-\overline{q^{\prime}}\right)^{2}}{n-1}}}{\sqrt{n}}$,

where $q_{i}^{\prime}$ is the CPC inlet flow rate during sample $i$, and $\overline{q^{\prime}}$ is the mean flow rate measured during the whole duration of sampling (for $n$ number of samples).

The uncertainty contribution in volume of AS particles due to CPC inlet flow rate is $\pm 0.95 \%$. This percentage is calculated using $\frac{u\left(q^{\prime}\right)}{\overline{q^{\prime}}} \%$. The corresponding standard uncertainty $u_{6}(V)$ (type $\mathrm{A}$ and normal distribution) is estimated to be $\pm 1.82 \times 10^{-19} \mathrm{~cm}^{3}$ using

$u_{6}(V)=\bar{v} \times \frac{u\left(q^{\prime}\right)}{\overline{q^{\prime}}} \times 0.01$

\section{Uncertainty in particle volume due to CPC dilution factor}

The CPC dilution factor is the ratio of aerosol sample flow rate (equivalent to $\mathrm{CPC}$ inlet flow rate) to sheath flow rate:

$\phi=\frac{\theta}{\theta^{\prime}}$,

where $\theta$ is the aerosol sample flow rate and $\theta^{\prime}$ is the DMA sheath flow rate (fixed at $0.48 \mathrm{~L} \mathrm{~min}^{-1}$ ). Both the sample flow rate and sheath flow rate are measured with the reference flow meter (Gilian Gilibrator2). Standard uncertainty due to CPC dilution factor $(u(\phi)$ at the inlet of CPC during sampling is estimated using

$u(\phi)=\frac{\sqrt{\frac{\sum_{i=1}^{n}\left(\phi_{i}-\bar{\phi}\right)^{2}}{n-1}}}{\sqrt{n}}$.

The uncertainty contribution in volume of ammonium sulfate due to the CPC dilution factor flow rate is $\pm 0.95 \%$. This percentage is calculated using $\frac{u(\phi)}{\bar{\phi}} \%$. The corresponding standard uncertainty $u_{7}(V)$ (type A and normal distribution) is estimated to be $\pm 1.82 \times 10^{-19} \mathrm{~cm}^{3}$ using

$u_{7}(V)=\bar{v} \times \frac{u(\phi)}{\bar{\phi}} \times 0.01$.

\section{Uncertainty in particle volume due to $\mathrm{CPC}$ counting accuracy}

CPC counting uncertainty $\left(u_{8}(V)^{\prime}\right)$ is directly taken from the CPC calibration certificate of the manufacturer, and CPC counting accuracy (for particle size $10-478 \mathrm{~nm}$ ) is further checked using a filter-based gravimetric technique $\left(u_{8}(V)^{\prime \prime}\right)$ (Aggarwal et al., 2013). The standard uncertainty in particle volume due to CPC counting accuracy in the measurement of particle volume $\left(u_{8}(V)\right)$ (type B uncertainty) is expressed as

$u_{8}(V)=\sqrt{\left(u_{8}(V)^{\prime}\right)^{2}+\left(u_{8}(V)^{\prime \prime}\right)^{2}}$.

The standard uncertainty $\left(u_{8}(V)\right)$ in volume measurement of AS particles due to CPC counting accuracy is estimated to be $\pm 12.3 \times 10^{-19} \mathrm{~cm}^{3}$. Here we discuss the detailed procedure of the calculation of CPC counting accuracy both using CPC certificate and the filter-based gravimetric technique.

From the manufacturer specification it has been reported that the CPC (TSI model 3788) particle concentration ac-

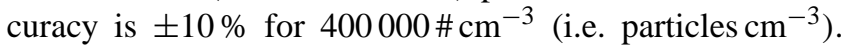
Therefore, the standard uncertainty (assuming $10 \%$ uncertainty, rectangular distribution and type B uncertainty) $\left(u_{8}(V)\right)$ in particle volume measurement due to CPC counting accuracy is

$u_{8}\left(V^{\prime}\right)=\bar{v} \times 10 \times 0.01 \times \frac{1}{\sqrt{3}}$. 
The standard uncertainty $u_{8}(V)^{\prime}$ for AS particles is estimated to be $\pm 1.1 \times 10^{-19} \mathrm{~cm}^{3}$.

The filter-based gravimetric technique has been discussed elsewhere (Aggarwal et al., 2013). Briefly, dried ammonium sulfate particles were introduced to SMPS with a sample flow rate of $0.6 \mathrm{~L} \mathrm{~min}^{-1}$ and sheath flow rate of $6 \mathrm{~L} \mathrm{~min}^{-1}$. Particles of size range $14-615 \mathrm{~nm}$ were segregated by DMA and number concentration was measured by CPC which was operated with a flow rate of $0.3 \mathrm{~L} \mathrm{~min}^{-1}$. Also, after DMA a Quartz filter $\left(47 \mathrm{~mm}\right.$ which was pre-baked at $450^{\circ}$, preconditioned and pre-weighted) was placed to collect particles with a flow rate of $0.3 \mathrm{~L} \mathrm{~min}^{-1}$ and simultaneously to measure the mass of the particles downstream of the DMA. After $30 \mathrm{~min}$ of particle sampling, the filter was conditioned and weighed.

Using CPC particle count data the CPC-derived particle volume was calculated as

$V^{\prime}=v \times \frac{\pi}{6} \times \sum_{i=1}^{105} d_{\mathrm{ve}, i}^{3} \times n_{i}^{\prime}$,

where $V^{\prime}$ is the total volume of the size distribution, $v$ is the flow volume that enters the CPC (calculated from CPC inlet flow and the time of flow), and $d_{\mathrm{ve}, i}$ and $n_{i}^{\prime}$ are the particle's mobility diameter and number concentration in bin $i$, respectively.

Based on the particle mass collected on the filter, and using the density of particle material (e.g. ammonium sulfate), we have calculated the volume of particles as

$V^{\prime \prime}=\frac{m}{\rho}$,

where $\rho$ is the density of particle material (e.g. in the case of ammonium sulfate, $1.769 \mathrm{~g} \mathrm{~cm}^{-3}$ ), and $m$ is the mass of the particles collected on the filter.

Using this approach, the uncertainty (estimated from the standard deviation of $V^{\prime}$ and $V^{\prime \prime}$ ) contribution due to CPC counting accuracy to the total volume of the AS particles is estimated to be $4.8 \%$. Therefore, the standard uncertainty $\left(\left(u_{8}(V)^{\prime \prime}\right.\right.$, assuming rectangular distribution and type B uncertainty) due to CPC counting accuracy in the measurement of particle volume is

$u_{8}(V)^{\prime \prime}=\bar{v} \times 4.8 \times 0.01 \times \frac{1}{\sqrt{3}}$.

The $u_{8}(V)^{\prime \prime}$ for AS particles is estimated to be $\pm 5.31 \times$ $10^{-19} \mathrm{~cm}^{3}$.

\section{Uncertainty due to assumption that equivalence of CPC- and QCM-derived particle volumes}

Both the CPC and QCM are placed equidistant downstream of the DMA. The inlet flow rates are equal for both of the instruments. Uncertainty because of the assumption of equivalency of CPC-derived volume (based on CMD of the distributions) and corresponding particle volume derived from the QCM (based on mass obtained from QCM and material density) is about $\pm 12 \%$. This is calculated based on the standard deviation between the CPC- and QCM-derived volumes. Therefore, the standard uncertainty $u_{9}(V)$ due to CPC and QCM volume equivalence (assuming rectangular distribution) in the measurement of particle volume is estimated as

$u_{9}(V)=\bar{v} \times 12 \times 0.01 \times \frac{1}{\sqrt{3}}$.

The $u_{9}(V)$ (type B and rectangular distribution) due to the assumption of CPC- and QCM-derived volume equivalence in AS particles is estimated to be $\pm 17.6 \times 10^{-19} \mathrm{~cm}^{3}$.

The combined relative standard uncertainty $u(V)$ including type A and type B uncertainty sources can be defined as

$\frac{u(V)}{V}=\sqrt{\sum_{i}\left(\frac{u_{\mathrm{A}, i}(V)}{V}\right)^{2}+\sum_{i}\left(\frac{u_{\mathrm{B}, i}(V)}{V}\right)^{2}}$,

where $u_{\mathrm{A}, i}(V)$ and $u_{\mathrm{B}, i}(V)$ are the standard uncertainty sources from type $\mathrm{A}$ and type $\mathrm{B}$, respectively as discussed in the above sections.

The estimated combined relative uncertainty in the volume measurement of AS particles is estimated to be \pm 0.12 .

Once the combined relative standard uncertainty for both the mass and volume is known, then the relative combined standard uncertainty in measurement of effective density of the particles can be estimated using Eq. (7).

Therefore, the combined standard uncertainties in the measurement of effective density of AS, SC and AN are estimated to be $1.76 \pm 0.24,2.08 \pm 0.19$ and $1.69 \pm 0.28 \mathrm{~g} \mathrm{~cm}^{-3}$, respectively. The percentage of estimated uncertainties in the measurement of the density of AS, SC and AN are calculated to be $13.6,9.13$ and $16.6 \%$, respectively.

The detailed uncertainty budget involving different components in the measurement of effective density of laboratory-generated aerosol particles (of AS, SC and AN) is summarized in Table 3. Among the individual uncertainty components (Fig. 2), the repeatability of particle mass obtained by QCM, QCM crystal frequency, CPC counting efficiency, and the equivalence of CPC- and QCM-derived volume are the major contributors to the expanded uncertainty (at $k=2$ ) in comparison to other components, e.g. diffusion correction, charge correction, CPC inlet flow rate, etc. The contribution of different components in the total uncertainty of effective density measurements varies with the nature or properties of different salt particles (i.e. hygroscopic property, solubility, etc). An extended study is needed to explain these differences in future.

\subsection{Ambient aerosol measurement}

After successful measurement of laboratory-generated aerosol particles, the experimental setup was used for the measurement of effective density of ambient aerosols. The 
measurements were carried out at the National Physical Laboratory (NPL, http://www.nplindia.org/), New Delhi, which can be considered as the representative site with a mixture of residential, biogenic, biomass-burning and traffic emissions. Because meteorological conditions/data during mid-November in Delhi are also known to be representative of the year-round mean data, therefore 1 week of measurements were conducted during 12-18 November (Wednesday-Tuesday), 2014.

Although we conducted density measurement from 8:00 to $19: 00 \mathrm{~h}$ (local time), here we report mid-day (10:0013:00 LT) data for which we have continuous data without any downtime in the measurements. Also the focus of the discussion here is to better understand the effect of the photochemistry of particles (secondary aerosols) versus their size/morphology and bulk composition on density, and thus mid-day data are considered here.

The mid-day mean over the 7 days of the measurement period of particle number concentration (ranged between $(3.1 \pm 0.52) \times 10^{4}$ to $(4.8 \pm 1.2) \times 10^{4}$ particles $\left.\mathrm{cm}^{-3}\right)$, count mean diameter $(82.8 \pm 6.5-125.7 \pm 11.7 \mathrm{~nm})$, effective density $\left(1.12 \pm 0.34-1.46 \pm 0.19 \mathrm{~g} \mathrm{~cm}^{-3}\right)$, relative humidity $(33.5 \pm 4.1-43.1 \pm 2.8 \%)$, temperature $(25.5 \pm 1.5-$ $\left.26.3 \pm 1^{\circ} \mathrm{C}\right)$ and gaseous species such as $\mathrm{CO}(230 \pm 50-555 \pm$ $\left.21 \mu \mathrm{g} \mathrm{m}^{-3}\right), \mathrm{O}_{3}\left(95.8 \pm 16-134 \pm 35 \mu \mathrm{g} \mathrm{m}^{-3}\right), \mathrm{NO}_{x}(12.6 \pm$ $\left.0.11-23.9 \pm 0.32 \mu \mathrm{g} \mathrm{m}^{-3}\right)$ and $\mathrm{SO}_{2}(14.5 \pm 2.2-30.3 \pm 6.3 \mu \mathrm{g}$ $\mathrm{m}^{-3}$ ) are shown in Fig. 4. The overall mean (i.e. mean of the mid-day mean) of the 7-day measurement period of effective density of particles is observed to be $1.28 \pm 0.12 \mathrm{~g} \mathrm{~cm}^{-3}$. This density measurement was carried out for ambient aerosol particle size distribution range of $10-478 \mathrm{~nm}$.

The observed mid-day particle effective density (range, $1.12-1.46 \mathrm{~g} \mathrm{~cm}^{-3}$; mean, $1.28 \mathrm{~g} \mathrm{~cm}^{-3}$ ) in New Delhi is similar to the particle effective density measurement data obtained from different sites around the globe. Yin et al. (2015) reported a size-resolved effective density of 50-400 nm urban particles using a TDMA-APM system in Shanghai during wintertime. The mean effective density was found to range between 1.36 and $1.55 \mathrm{~g} \mathrm{~cm}^{-3}$ which showed increasing trend with particle diameter. They observed that for $50 \mathrm{~nm}$ particles, the effective density increased rapidly from $1.35 \mathrm{~g} \mathrm{~cm}^{-3}$ at 10:00 LT to $1.51 \mathrm{~g} \mathrm{~cm}^{-3}$ at 13:00 LT corresponding to a burst of nucleation and Aitken mode particles.

Khlystov et al. (2004) compared the TEOM PM 2.5 mass concentrations with volume concentrations from the SMPSAPS data, and estimated an effective density of $1.52 \pm$ $0.26 \mathrm{~g} \mathrm{~cm}^{-3}$ of urban aerosols during the Pittsburgh Air Quality Study (PAQS) in summertime. This density is close to $1.56 \mathrm{~g} \mathrm{~cm}^{-3}$, the density estimated from the average aerosol bulk chemical composition during the PAQS study. Further, the DMPS-APS and TEOM approach has been used by Pitz et al. (2008) to determine particle $(<2.5 \mu \mathrm{m})$ effective density at an urban site in Augsburg, Germany. They reported minimum particle density in the morning and afternoon $\left(\sim 1.5 \mathrm{~g} \mathrm{~cm}^{-3}\right)$, and a maximum $\left(\sim 1.8 \mathrm{~g} \mathrm{~cm}^{-3}\right)$ during mid-day. They suggested that the minima represent fresh primary aerosol emissions, which were related to traffic soot particles with agglomerate structure, whereas the maximum is likely due to increased secondary particle production during mid-day hours and the presence of more aged particles.

Geller et al. (2006) determined effective densities of atmospheric aerosols over a size range of 50-414 nm in various locations of the Los Angeles Basin using a SMPS-APM technique. They reported an effective density of unity or more for $50 \mathrm{~nm}$ particles, indicative of their spherical nature. It was suggested that the lower density of marine aerosols may be due to the presence of a significant amount of organics. Riverside aerosols, with an effective density as high as 1.4$1.5 \mathrm{~g} \mathrm{~cm}^{-3}$ for this particle size especially during mid-day hours were thought to be generated predominantly from photochemical reactions.

Kannosto et al. (2008) reported the mode-resolved density of ultrafine atmospheric particles (nucleation, Aitken and accumulation mode) measured using the SMPS or DMPS-ELPI technique for 2 weeks during early summer in a boreal forest environment. The particle density for accumulation mode varied from $1.1-2.0 \mathrm{~g} \mathrm{~cm}^{-3}$ (average $1.5 \mathrm{~g} \mathrm{~cm}^{-3}$ ) and for Aitken mode from 0.4 to $2.0 \mathrm{~g} \mathrm{~cm}^{-3}$ (average $0.97 \mathrm{~g} \mathrm{~cm}^{-3}$ ). The density of nucleation mode particles decreased during the growth process. The density values for $15 \mathrm{~nm}$ particles were $1.2-1.5 \mathrm{~g} \mathrm{~cm}^{-3}$ and for grown $30 \mathrm{~nm}$ particles 0.5 $1 \mathrm{~g} \mathrm{~cm}^{-3}$. They suggested that this observation is consistent with the present knowledge that the condensing species are semi-volatile organics emitted from the boreal forest.

The above discussions suggest that particle density depends more on particle chemical composition (which changes rapidly while particle growth occurs during the midday period) and morphology than on particle size. To further check this hypothesis with the results in this study, we compared ambient gaseous composition with observed densities.

Figure 5 displays the mean particle effective density versus count mean diameter over the size range $10-478 \mathrm{~nm}$ observed in mid-day during the sampling days. In each box, the line within the box shows the median effective density value which corresponds to a CMD value, the top and bottom lines of the box show the upper and lower quartiles (the 75th and 25 th percentiles) and the top and bottom of the whiskers are set to 90 and 10 percentile. Considering more than 100 scans each day collectively, it was less often evident that the effective density increased with the particle mobility diameter, with a mean of $1.12 \pm 0.3 \mathrm{~g} \mathrm{~cm}^{-3}$ at $82.84 \pm 6.51 \mathrm{~nm}$ and $1.46 \pm 0.2 \mathrm{~g} \mathrm{~cm}^{-3}$ at $86.39 \pm 4.49 \mathrm{~nm}$. This density versus size trend is not exactly the same as observed by Yin et al. (2015) that material density generally increased with particle size in the range of $50-400 \mathrm{~nm}$.

Figure 4a shows 7 consecutive days' mid-day mean effective density and mean CMD of particles during the sampling period. On the first 5 days, the effective density and particle size (CMD) show a positive correlation coefficient $(r=0.61)$; however on the remaining 2 days they show a 

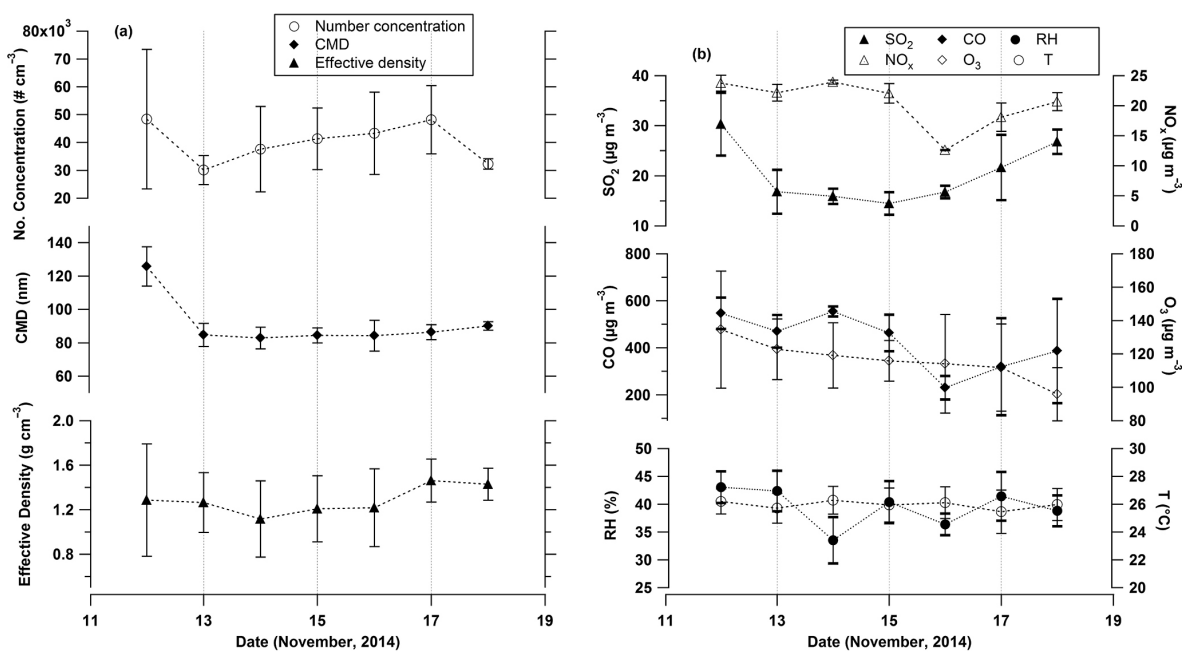

Figure 4. Mid-day (10:00-13:00 LT) mean (bar represents standard deviation) of (a) number concentration, count mean diameter (CMD), effective density, and (b) relative humidity, temperature and gas concentrations $\left(\mathrm{CO}, \mathrm{O}_{3}, \mathrm{SO}_{2}, \mathrm{NO}_{x}\right)$.

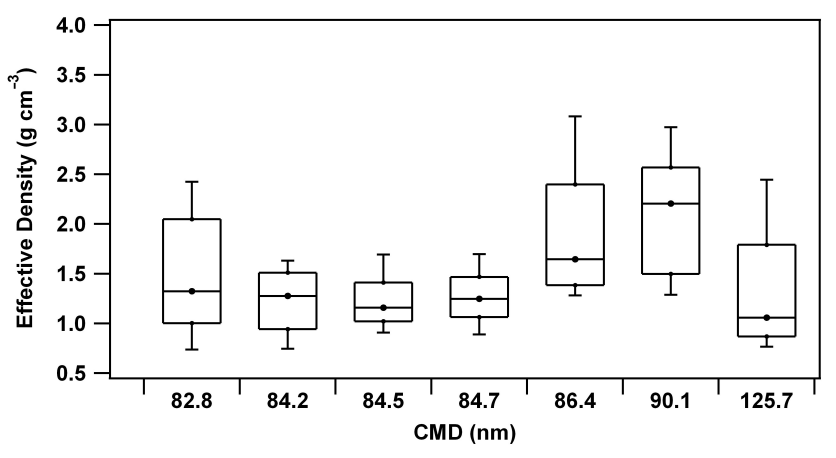

Figure 5. Measured effective density of ambient particles versus their size (count mean diameter, CMD) during mid-day (10:0013:00 LT) of 7 consecutive days of sampling. In each box, the midline shows the median effective density value for the corresponding CMD value, the top and bottom show the upper and lower quartiles (the 75th and 25th percentiles), and the top and bottom of the whiskers are set to 90th and 10th percentile, respectively.

negative trend with overall (during the 7 days) correlation coefficient $r=0.14$. Large variations in particle number concentration including in CMD and effective density were observed on the first day, whereas on the last day these variations were observed to be minimized.

Among gaseous species (Fig. 4b), mid-day mean concentration of $\mathrm{O}_{3}$ shows a decreasing trend with the sampling days. Interestingly, $\mathrm{CO}$ and $\mathrm{NO}_{x}$ present a similar trend with the sampling days with first-day (12 November) maximum and fifth-day minimum (16 November). Mid-day mean concentration of both these species shows a continuous increasing trend during the last 3 days of the campaign (16-18 November). A strong correlation of the 7-day midday mean concentration between these two gases is obtained $(r=0.96)$, suggesting their common source, possibly from traffic-related emission.

Further, day five (16 November) was Sunday. Recently Gour et al. (2015) published a detailed report based on 5 years of observation that in New Delhi CO and $\mathrm{NO}_{x}$ concentration is lower on weekends and public holidays than during working days. This further suggested that both of the species are related with traffic source.

On the other hand, $\mathrm{SO}_{2}$ mid-day mean concentration decreases from the first day of the campaign to the middle of the campaign (15 November) and then shows continuous increase to the end of the campaign. Among all the gaseous species (Table 5), $\mathrm{SO}_{2}$ presents a positive correlation coefficient $(r=0.59)$ with particle effective density. Relative humidity $(\mathrm{RH})$ also shows a positive correlation coefficient $(r=0.52)$ with particle effective density. This suggests that condensation of sulfates and water-vapour most likely occurred on smaller particles, hence influencing the density of the particles. It is also evident that mid-day particle mean diameter shows a good/strong correlation with ozone $(r=0.58), \mathrm{SO}_{2}(r=0.81)$ and $\mathrm{RH}(r=0.51)$, while it shows poor correlations with the $\mathrm{NO}_{x}(r=0.35)$ and $\mathrm{CO}$ $(r=0.40)$. This is consistent with the theory of the atmospheric photo-oxidation process of $\mathrm{SO}_{2}$ that in the presence of sunlight and water vapour, $\mathrm{O}_{3}$ forms an $\mathrm{OH}$ radical which oxidizes $\mathrm{SO}_{2}$ to $\mathrm{SO}_{3}$ and then forms $\mathrm{H}_{2} \mathrm{SO}_{4}$ vapour (Seinfeld and Pandis, 2006). These vapours contribute to the condensational growth of aerosol particles, and hence to the increasing effective density of particles. 
Table 5. Correlation coefficient $(r)$ between mid-day (10:0013:00 LT) mean of ambient particle effective density and other atmospheric constituents during 7 days of sampling in New Delhi in November.

\begin{tabular}{lrrrrrrr}
\hline$r$ & $\mathrm{O}_{3}$ & $\mathrm{CO}$ & $\mathrm{NO}_{x}$ & $\mathrm{SO}_{2}$ & $\mathrm{RH}$ & $T$ & $\rho_{\text {eff }}$ \\
\hline $\mathrm{O}_{3}$ & 1 & & & & & & \\
$\mathrm{CO}$ & 0.54 & 1 & & & & & \\
$\mathrm{NO}_{x}$ & 0.37 & 0.96 & 1 & & & & \\
$\mathrm{SO}_{2}$ & 0.04 & 0.13 & 0.20 & 1 & & & \\
$\mathrm{RH}$ & 0.32 & 0.10 & 0.21 & 0.45 & 1 & & \\
$T$ & 0.26 & 0.41 & 0.22 & 0.08 & -0.54 & 1 & \\
$\rho_{\text {eff }}$ & -0.48 & -0.41 & -0.20 & 0.59 & 0.52 & -0.68 & 1 \\
\hline
\end{tabular}

\section{Conclusions}

We have presented a method to measure the effective density of aerosol particles of a size range from 10 to $478 \mathrm{~nm}$. We used an SMPS-QCM approach to measure particle effective density, for which particle volume is calculated from size distribution data of the SMPS and simultaneously mass concentration of particles is obtained from the QCM. This approach is simple because of the use of real-time aerodynamic instrument (QCM). The method is successfully tested for laboratory-generated particles from the solutions of standard materials (inorganic salts of known densities). Also the setup is successfully applied for ambient measurement of particle effective density in New Delhi. To our knowledge, this is the first time that a detailed uncertainty budget of particle effective density measurement using the SMPSQCM technique has been discussed. The discussed uncertainty measurement method can be applied to similar instrumental approaches (such as TDMA/SMPS/DMPS/APSAPM/ELPI/TEOM, etc.) used for particle effective density measurement. Among individual uncertainty components, repeatability of the particle mass obtained by QCM, the QCM crystal frequency, CPC counting accuracy and equivalence of CPC- and QCM-derived volume are the major contributors to the expanded uncertainty (at $k=2$ ) in comparison to other components. This suggests that minimizing the calibration uncertainties of the QCM (i.e. in particle mass sensing) and CPC (i.e. in particle counting) can result in reducing the uncertainty of particle density measurement. Using this approach, the effective density of laboratorygenerated ammonium sulfate, sodium chloride and ammonium nitrate particles with combined uncertainty is found to be $1.76 \pm 0.24( \pm 13.6 \%), 2.08 \pm 0.19( \pm 9.13 \%)$ and $1.69 \pm$ $0.28 \mathrm{~g} \mathrm{~cm}^{-3}( \pm 16.6 \%)$, respectively. The ambient measurements (of particle size range: $10-478 \mathrm{~nm}$ ) revealed that in general, effective density of ambient aerosol increases with the increase in particle size during mid-day hours during the sampling days in November in New Delhi. However, this particle growth is likely governed by mid-day photochemistry of the sulfate secondary aerosol formation process. The mid-day mean effective density of ambient parti- cles (10-478 nm) during the 7 days of sampling is obtained to be $1.28 \pm 0.12 \mathrm{~g} \mathrm{~cm}^{-3}$. Our results of mid-day measurement of ambient particle effective density with other atmospheric constituents suggest that particle effective density is largely dependent on particle chemistry.

Acknowledgements. The authors thank the Director of the CSIR-National Physical Laboratory, New Delhi for providing all instrumental facilities and support. B. Sarangi thanks the Department of Science and Technology, Government of India, New Delhi for awarding him an INSPIRE fellowship.

Edited by: A. Kokhanovsky

\section{References}

Aggarwal, S. G., Sarangi, B., Kumar, S., and Gupta, P. K.: A simplified approach to calibrate condensation particle counter for aerosol number concentration measurement, in: 8th International Conference on Advances in Metrology (AdMet-2013) and PreAdMet Workshop, 20-23 February 2013, New Delhi, India, OP26, P100-101, 2013.

Baron, P. A. and Willeke, K.: Gas and particle motion, in: Aerosol Measurement: Principles, Techniques, and Applications, edited by: Baron, P. A. and Willeke, K., Wiley, New York, 61-97, 2001.

Buonanno, G., Dell'Isola, M., Stabile, L., and Viola, A.: Uncertainty budget of the SMPS-APS system in the measurement of $\mathrm{PM}_{10}, \mathrm{PM}_{2.5}$ and $\mathrm{PM}_{1}$, Aerosol Sci. Tech., 43, 1130-1141, 2009.

Geller, M., Biswas, S., and Sioutas, C.: Determination of particle effective density in urban environments with a differential mobility analyzer and aerosol particle mass analyzer, Aerosol Sci. Tech., 40, 709-723, doi:10.1080/02786820600803925, 2006.

Gour, A. A., Singh, S. K., Tyagi, S. K., and Mandal, A.: Variation in parameters of ambient air quality in National Capital Territory (NCT) of Delhi (India), Atmospheric and Climate Sciences, 5, 13-22, doi:10.4236/acs.2015.51002, 2015.

Gysel, M., Laborde, M., Olfert, J. S., Subramanian, R., and Gröhn, A. J.: Effective density of Aquadag and fullerene soot black carbon reference materials used for SP2 calibration, Atmos. Meas. Tech., 4, 2851-2858, doi:10.5194/amt-4-2851-2011, 2011.

Hand, J. L. and Kreidenweis, S. M.: A new method for retrieving particle refractive index and effective density from aerosol size distribution data, Aerosol Sci. Tech., 36, 1012-1026, 2002.

Hinds, W. C.: Aerosol Technology: Properties, Behavior, and Measurement of Airborne Particles, Wiley, New York, 1999.

Horton, K. D., Ball, M. H. E., and Mitchell, J. P.: The calibration of a California Measurements PC-2 quartz crystal cascade impactor (QCM), J. Aerosol Sci., 23, 505-524, 1992.

Jimenez, J. L., Bahreini, R., Cocker, D. R., Zhuang, H., Varutbangkul, V., Flagan, R. C., Seinfeld, J. H., O'Dowd, C. D., and Hoffmann, T.: New particle formation from photooxidation of diiodomethane $\left(\mathrm{CH}_{2} \mathrm{I}_{2}\right)$, J. Geophys. Res., 108, 4318, doi:10.1029/2002JD002452, 2003.

Johnson, T. J., Olferta, J. S., Cabot, R., Treacy, C., Yurteri, C. U., Dickens, C., McAughey, J., and Symonds, J. P. R.: Steady- 
state measurement of the effective particle density of cigarette smoke, J. Aerosol Sci., 75, 9-16, 2014.

Kannosto, J., Virtanen, A., Lemmetty, M., Mäkelä, J. M., Keskinen, J., Junninen, H., Hussein, T., Aalto, P., and Kulmala, M.: Mode resolved density of atmospheric aerosol particles, Atmos. Chem. Phys., 8, 5327-5337, doi:10.5194/acp-8-5327-2008, 2008.

Katrib, Y., Martin, S. T., Rudich, Y., Davidovits, P., Jayne, J. T., and Worsnop, D. R.: Density changes of aerosol particles as a result of chemical reaction, Atmos. Chem. Phys., 5, 275-291, doi:10.5194/acp-5-275-2005, 2005.

Kelly, W. P. and McMurry, P. H.: Measurement of particle density by inertial classification of differential mobility analyzergenerated monodisperse aerosols, Aerosol Sci. Tech., 17, 199212, doi:10.1080/02786829208959571, 1992.

Khlystov, A., Stanier, C., and Pandis, S. N.: An algorithm for combining electrical mobility and aerodynamic size distributions data when measuring ambient aerosol, Aerosol Sci. Tech., 38, 229238, 2004.

Kim, S., Woo, K., Liu, B., and Zachariah, M.: Method of measuring charge distribution of nanosized aerosols, J. Coll. Interface Sci., 282, 46-57, 2005.

Kostenidou, E., Pathak, R. K., and Pandis, S. N.: An algorithm for the calculation of secondary organic aerosol density combining AMS and SMPS data, Aerosol Sci. Tech., 41, 1002-1010, doi:10.1080/02786820701666270, 2007.

Lee, S. Y., Widiyastuti, W., Tajima, N., Iskandar, F., and Okuyama, K.: Measurement of the effective density of both spherical aggregated and ordered porous aerosol particles using mobility- and mass-analyzers, Aerosol Sci. Tech., 43, 136-144, doi:10.1080/02786820802530524, 2009.

Malloy, Q. G. J., Nakao, S., Qi, L., Austin, R., Stothers, C., Hagino, H., and Cocker III, D. R.: Real-time aerosol density determination utilizing a modified scanning mobility particle sizeraerosol particle mass analyzer system, Aerosol Sci. Tech., 43, 673-678, 2009.

Maricq, M. and $\mathrm{Xu}, \mathrm{N}$. : The effective density and fractal dimension of soot particles from premixed flames and motor vehicle exhaust, J. Aerosol Sci., 35, 1251-1274, 2004.

McMurry, P. H., Wang, X., Park, K., and Ehara, K.: The relationship between mass and mobility for atmospheric particles: a new technique for measuring particle density, Aerosol Sci. Tech., 36, 227-238, 2002.

Nakao, S., Tang, P., Tang, X., Clark, C. H., Seo, Li. Q., E., AsaAwuku, A., and Cocker III, D.: Density and elemental ratios of secondary organic aerosol: application of a density prediction method, Atmos. Environ., 68, 273-277, 2013.

Olfert, J. S., Symonds, J. P. R., and Collings, N.: The effective density and fractal dimension of particles emitted from a light-duty diesel vehicle with a diesel oxidation catalyst, J. Aerosol Sci., 38, 69-82, 2007.

Ovigneur, B., Landgraf, J., Snel, R., and Aben, I.: Retrieval of stratospheric aerosol density profiles from SCIAMACHY limb radiance measurements in the $\mathrm{O}_{2}$ A-band, Atmos. Meas. Tech., 4, 2359-2373, doi:10.5194/amt-4-2359-2011, 2011.

Quiros, D., Hu, S. H., Hu, S. S., Lee, E. S., Sardar, S., Wang, X. L., Olfert, J. S., Jung, H. J., Zhu, Y. F., and Huai, T.: Particle effective density and mass during steady-state operation of GDI, PFI, and diesel passenger cars, J. Aerosol Sci., 83, 39-54, 2015.
Pitz, M., Schmid, O., Heinrich, J., Birmili, W., Maguhn, J., Zimmermann, R., Wichmann, H.-E., Peters, A., and Cyrys, J.: Seasonal and diurnal variation of $\mathrm{PM}_{2.5}$ apparent particle density in urban air in Augsburg, Germany, Environ. Sci. Technol., 42, 5087-5093, 2008.

Rissler, J., Nordin, E. Z., Eriksson, A. C., Nilsson, P. T., Frosch, M., Sporre, M. K., Wierzbicka, A., Svenningsson, B., Löndahl, J., Messing, M. E., Sjogren, S., Hemmingsen, J. G., Loft, S., Pagels, J. H., and Swietlicki, E.: Effective density and mixing state of aerosol particles in a near-traffic urban environment, Environ. Sci. Technol., 48, 6300-6308, doi:10.1021/es5000353, 2014.

Sarangi, B., Aggarwal, S. G., and Gupta, P. K.: Estimation of uncertainty in particle size measurement using differential mobility analyzer, 3rd National Conference on Advances in Metrology (AdMet), 19-21 February 2014, Patiala, Punjab, India, OP1, P51-52, 2014.

Sarangi, B., Aggarwal, S. G., and Gupta, P. K.: A simplified approach to calculate particle growth rate due to self-coagulation, scavenging and condensation using SMPS measurements during a particle growth event in New Delhi, Aerosol Air Qual. Res., 15, 166-179, 2015.

Schkolnik, G., Chand, D., Hoffer, A., Andreae, M. O., Erlick, C., Swietlicki, E., and Rudich, Y.: Constraining the density and complex refractive index of elemental and organic carbon in biomass burning aerosol using optical and chemical measurements, Atmos. Environ., 41, 1107-1118, 2007.

Schmid, O., Chand, D., Karg, E., Guyon, P., Frank, G. P., Swietlicki, E., and Andreae, M. O.: Derivation of the density and refractive index of organic matter and elemental carbon from closure between physical and chemical aerosol properties, Environ. Sci. Technol., 43, 1166-1172, 2009.

Seinfeld, J. H. and Pandis, S. N.: Atmospheric Chemistry and Physics: From Air Pollution to Climate Change, 2nd edn., John Wiley \& Sons, Inc., New Jersey, 2006.

Sioutas, C., Abt, E., Wolfson, J. M., and Koutrakis, P.: Evaluation of the measurement performance of the scanning mobility particle sizer and aerodynamic particle sizer, Aerosol Sci. Tech., 30, 8492, 1999.

Spencer, M. T., Shields, L. G., and Prather, K. A.: Simultaneous measurement of the effective density and chemical composition of ambient aerosol particles, Environ. Sci. Technol., 41, 13031309, doi:10.1021/es061425+, 2007.

Svenningsson, B., Rissler, J., Swietlicki, E., Mircea, M., Bilde, M., Facchini, M. C., Decesari, S., Fuzzi, S., Zhou, J., Mønster, J., and Rosenørn, T.: Hygroscopic growth and critical supersaturations for mixed aerosol particles of inorganic and organic compounds of atmospheric relevance, Atmos. Chem. Phys., 6, 1937-1952, doi:10.5194/acp-6-1937-2006, 2006.

Tang, I. N. and Munkelwitz, H. R.: Water activities, densities, and refractive-indexes of aqueous sulphates and sodium-nitrate droplets of atmospheric importance, J. Geophys. Res., 99, 18801-18808, 1994.

Virtanen, A., Ristimäki, J., Marjamäki, M., Vaaraslahti, K., Keskinen, J., and Lappi, M.: Effective Density of Diesel Exhaust Particles as a Function of Size, SAE Technical Paper 2002-01-0056, Society of Automotive Engineers 2002 World Congress, Detroit, USA, doi:10.4271/2002-01-0056, 2002. 
Wiedensohler, A.: An approximation of the bipolar charge distribution for particles in the submicron size range, J. Aerosol Sci., 19, 387-389, 1988.

Yin, Z., Ye, X., Jiang, S., Tao, Y., Shi, Y., Yang, X., and Chen, J.: Size-resolved effective density of urban aerosols in Shanghai, Atmos. Environ., 100, 133-140, 2015.
Zelenyuk, A., Cai, Y., and Imre, D.: From agglomerates of spheres to irregularly shaped particles: Determination of dynamic shape factors from measurements of mobility and vacuum aerodynamic diameters, Aerosol Sci. Technol., 40, 197-217, 2006. 